\title{
Hay fever as a Christmas gift
}

Gassner, Markus ; Gehrig, Regula ; Schmid-Grendelmeier, Peter

DOI: https://doi.org/10.1056/NEJMc1214426

Posted at the Zurich Open Repository and Archive, University of Zurich ZORA URL: https://doi.org/10.5167/uzh-73223

Journal Article

Published Version

Originally published at:

Gassner, Markus; Gehrig, Regula; Schmid-Grendelmeier, Peter (2013). Hay fever as a Christmas gift. New England Journal of Medicine, 368(4):393-394.

DOI: https://doi.org/10.1056/NEJMc1214426 
tion of the paralyzed muscle. Rotatory or torsional nystagmus is typically associated with medullary lesions and would not be expected in a patient with peripheral-nerve involvement.

Lea Pollak, M.D.

Assaf Harofeh Medical Center

Zerifin, Israel

lea.pollak@gmail.com

No potential conflict of interest relevant to this letter was reported.

1. Leigh RJ, Zee DS. The neurology of eye movements. 4th ed. New York: Oxford University Press, 2006.

DOI: $10.1056 /$ NEJMc1213034

THE AUTHORS REPLY: We appreciate the additional points raised by Rao et al. and would underscore the importance of early initiation of antitoxin treatment in cases of suspected botulism. A retrospective analysis of 132 cases of foodborne botulism reported to the CDC from 1973 through 1980 showed a median hospital stay of 10 days if patients received antitoxin within 24 hours after symptoms began, as compared with 41 days if antitoxin was received after 24 hours of symptoms and 56 days if they did not receive antitoxin. ${ }^{1}$ Better outcomes were also associated with earlier treatment in a 2006 botulism outbreak involving 209 patients in Thailand who had consumed home-canned bamboo shoots. ${ }^{2-4}$

We also wish to correct two statements in our article. The statement beginning "Foodborne botulism classically occurs after ingestion of spores" should have read "Foodborne botulism occurs after ingestion of botulinum toxin." We referred to the availability of "intravenous equine trivalent antitoxin (for types A, B, and E) or bivalent antitoxin (for types A and B)" from state health departments. As pointed out by Rao et al., heptavalent antitoxin is the only antitoxin currently available. Our patient was hospitalized before the availability of this particular antitoxin.

The nystagmus was described as rotatory by an observer, but unfortunately, the authors were not present to observe this. We agree with Dr. Pollak that gaze-paretic nystagmus would be more likely.

Miten Vasa, M.D.

University of California, Irvine

Orange, CA

miten.vasa@gmail.com

Thomas E. Baudendistel, M.D.

Kaiser Permanente, Oakland

Oakland, CA

Since publication of their article, the authors report no further potential conflict of interest.

1. Tacket CO, Shandera WX, Mann JM, Hargent NT, Blake BA. Equine antitoxin use and other factors that predict outcome in type A foodborne botulism. Am J Med 1984;76:794-8.

2. Kongsaengdao S, Samintarapanya $\mathrm{K}$, Rusmeechan $\mathrm{S}$, et al. An outbreak of botulism in Thailand: clinical manifestations and management of severe respiratory failure. Clin Infect Dis 2006;43:1247-56.

3. Wongtanate M, Sucharitchan N, Tantisiriwit K, et al. Signs and symptoms predictive of respiratory failure in patients with foodborne botulism in Thailand. Am J Trop Med Hyg 2007;77: 386-9.

4. Witoonpanich R, Vichayanrat E, Tantisiriwit K, et al. Survival analysis for respiratory failure in patients with food-borne botulism. Clin Toxicol (Phila) 2010;48:177-83.

DOI: 10.1056/NEJMc1213034

\section{Hay Fever as a Christmas Gift}

TO THE EDITOR: Changing patterns of allergic sensitization to pollens have been noted around the world among schoolchildren. We report one associated with unusual winter allergic symptoms in Switzerland. Our group has gathered information on allergic symptoms and serologic findings among 15-year-olds attending school in Grabs, a village in eastern Switzerland, ${ }^{1}$ from 1983 through 2007. ${ }^{2}$ We measured IgE antibodies to 103 molecular allergens (using ImmunoCAP ISAC) in serum samples obtained from 54 students in 1986 and from 46 students in $2006 .{ }^{3}$ In 2010, we retested 12 of the former students (then 39 years old) who in 1986 had had positive IgE antibodies to inhalant allergens from birch trees, grass, house-dust mites, or cats. Atmospheric pol- len levels were measured with the use of Hirsttype pollen traps.

IgE antibodies against the main allergen of alder trees (Aln g 1), which were not detected in any child in 1986 , were found in $10.9 \%$ of unselected healthy schoolchildren in 2006. This increased prevalence of sensitization was not seen with pollen of other trees, such as birch, hazel, ash, or plane. Among the 12 former students who were tested at the ages of 15 and 39 years, 3 (25\%) showed newly detectable IgE antibodies to alder pollen in 2010. Although none of the schoolchildren reported having had allergic symptoms in December from 1983 through 1986, 6 students had such symptoms in 2006; all were sensitized to alder pollen. Because allergic symp- 


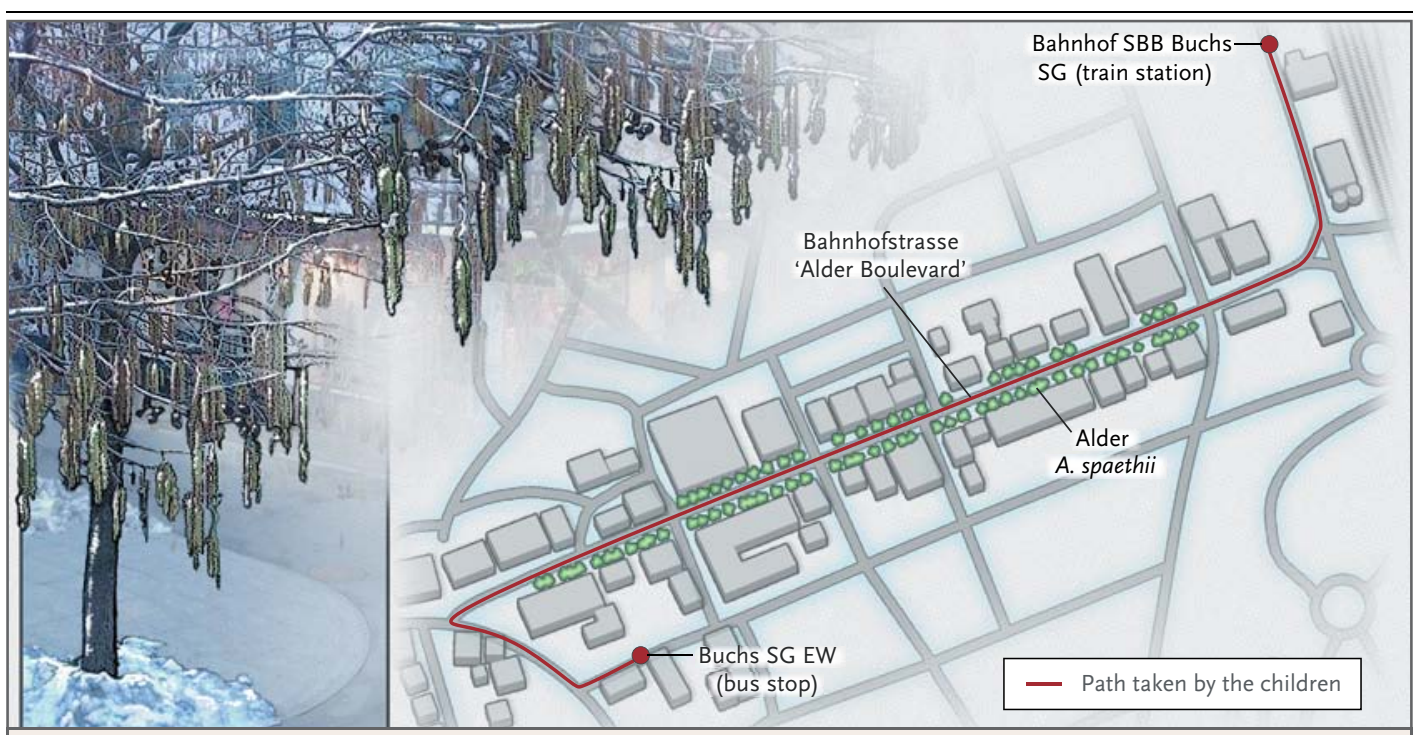

Figure 1. Boulevard with Alder Trees Flowering in December.

The map shows part of the route that children take on their way to school (not shown) by bus or on foot. Shown on the map are the hybrid alder trees. On the left is an image of one of the hybrid trees in full blossom in December.

toms are thought to be uncommon in winter, it seems likely that the rhinoconjunctivitis in these children might have been attributed to a common cold.

Just over a decade ago, 96 hybrid trees with high winter resistance (Alnus x spaethii: A. japonicax A. subcordata) were planted along a main boulevard in Buchs, where children walk or ride the bus on their way to school in Grabs. This leads to almost daily pollen exposure during the flowering season, which for alders in this region of Switzerland is in December (Fig. 1). Near Christmas of 2011, large amounts of alder pollen were noted in the trap. It seems likely that this newly introduced plant species, along with changing temperatures and street lighting, may have influenced the release of pollens in winter, ${ }^{4}$ which led to the allergic sensitization to alder and the gift to many children of a runny nose at Christmas. ${ }^{5}$

Markus Gassner, M.D.

Internal Medicine, Allergology, and Clinical Immunology Grabs, Switzerland

Regula Gehrig, Ph.D.

MeteoSwiss

Zurich, Switzerland

Peter Schmid-Grendelmeier, M.D.

University Hospital of Zurich

Zurich, Switzerland

peter.schmid@usz.ch

Disclosure forms provided by the authors are available with the full text of this letter at NEJM.org.

1. Gassner M. Frequency of allergic diseases in schoolchildren of a rural population in regard to occupational counseling. Z Haut Geschlechtskrankheiten 1985;150:649.
2. Braun-Fahrländer $C$, Gassner $M$, Grize $L$, et al. Prevalence of hay fever and allergic sensitization in farmer's children and their peers living in the same rural community. Clin Exp Allergy 1999; 29:28-34

3. Skamstrup Hansen K, Poulsen LK. Component resolved testing for allergic sensitization. Curr Allergy Asthma Rep 2010;10: 340-8.

4. Körner C, Basler D. Plant science: phenology under global warming. Science 2010;327:1461-2.

5. Sly PD, Boner AL, Björksten B, et al. Early identification of atopy in the prediction of persistent asthma in children. Lancet 2008;372:1100-6.

This letter was published on December 21, 2012, at NEJM.org.

DOI: $10.1056 /$ NEJMc1214426

Correspondence Copyright ( 2 2012, 2013 Massachusetts Medical Society.

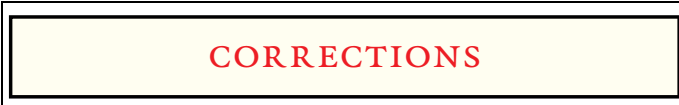

Current Concepts: Accidental Hypothermia (November 15, 2012; 367:1930-8). In the Accidental Hypothermia in Special Situations section, under "Avalanche Burial without Vital Signs" (page 1936), the first sentence should have read, "The maximum reported cooling rate in a person who had been completely buried in an avalanche was $9^{\circ} \mathrm{C}\left(16.2^{\circ} \mathrm{F}\right)$ per hour," rather than “. . . $9^{\circ} \mathrm{C}\left(48^{\circ} \mathrm{F}\right)$ per hour." The article is correct at NEJM.org.

The Eyes Have It (September 6, 2012;367:938-43). A correction is described in the Correspondence section of this issue of the Journal (The Eyes Have It [January 24, 2013:368:392-3]). The article is correct at NEJM.org.

Anterior Colporrhaphy versus Transvaginal Mesh for PelvicOrgan Prolapse (May 12, 2011;364:1826-36). In the Study Design subsection of Methods, the final paragraph (page 1828) should have read, "As cosponsor of the trial, the manufacturer of the mesh kit reviewed the original study protocol and a presubmission draft of the manuscript. The manufacturer did not provide the products used in the trial and had no involvement in data collection and analysis or in the decision to submit the results for publication." The article is correct at NEJM.org. 